\title{
Investigation of strengthening mechanism of commercially pure titanium joints fabricated by autogenously laser beam welding and laser-MIG hybrid welding processes
}

\author{
Ruifeng $\mathrm{Li}^{1} \cdot$ Feng Zhang ${ }^{1} \cdot$ Tianzhu Sun $^{2} \cdot$ Bin Liu $^{1} \cdot$ Shujin Chen ${ }^{1} \cdot$ Yingtao Tian $^{3}$
}

Received: 26 July 2018 / Accepted: 22 October 2018 / Published online: 1 November 2018

(C) The Author(s) 2018

\begin{abstract}
In this study, in order to achieve a better understanding of the strengthening mechanism in the commercially pure (CP) Ti welds, autogenously laser beam and laser-MIG hybrid welding of $4.2 \mathrm{~mm}$ thick CP-Ti plates were performed and the correlation between microstructure, texture distribution and the mechanical properties were systematically investigated. Microstructural coarsening and increase in microhardness were observed in the HAZ and WZ. The tensile test results suggested the base metal was the weak point of the joint for both welding conditions. The EBSD observations confirmed that a large number of $\{10 \overline{1} 2\}$ and $\{11 \overline{2} 2\}$ twin grains occurred in the HAZ and WZ of both welded joints, while a higher concentration of these twin grains were found in the laser-MIG hybrid joints. High concentration of the twin grain boundaries can act as barrier to stop dislocation slip during deformation and therefore contribute to the strengthening of the welds. The existence of very small twin grains and acicular $\alpha$ phase in HAZ and WZ would equivalently reduce the averaged grain size and therefore induce an increase in strength based on Hall-Petch's law. In addition, the averaged Schmid factor of BM is higher than that of the WZ and HAZ in both welding joints suggesting that the grain boundary sliding will take place preferably in BM during deformation so that the necking and fracture occurred in base metal during tensile tests of both welding joint specimens.
\end{abstract}

Keywords Laser beam welding · Laser-MIG hybrid welding · Commercially pure titanium · Strengthening mechanism · Microstructure $\cdot$ Texture $\cdot$ Mechanical property

\section{Introduction}

Commercially pure titanium (CP-Ti) has been widely used in many industries, such as aerospace, defense, petrol-chemical, nuclear energy and medical applications, due to its high specific strength, excellent corrosion resistance, high temperature performance and excellent biocompatibility [1-3]. With

\section{Ruifeng Li}

li_ruifeng@just.edu.cn

Yingtao Tian

y.tian12@lancaster.ac.uk

1 School of Materials Science and Engineering, Jiangsu University of Science and Technology, Zhenjiang, Jiangsu 212003, People's Republic of China

2 School of Materials, The University of Manchester, Manchester M13 9PL, UK

3 Department of Engineering, Lancaster University, Bailrigg, Lancaster LA1 4YW, UK increased usage, joining of titanium has become necessary and more and more important in many circumstances [4-6]. In fusion welding of pure titanium and its alloys, it is very easy to have defects such oxidation of surface and gas inclusion. This is because titanium is a relatively active metal and has a strong tendency to absorb oxygen, hydrogen and nitrogen at high temperature. So, the weld zone needs to be well protected to prevent titanium from absorbing these gas elements resulting in interstitial hardening which is harmful for the mechanical performance of the welds [7-10]. Autogenously laser beam welding of engineering components is receiving great attention as it offers advantages of smaller distortions and lower residual stresses due to lower heat input comparing to arc welding. However, it has negative issues such as gap bridging and brittle phase formation due to high cooling rate [11-13]. To overcome these problems, laser-arc hybrid welding was developed by combining the benefits of arc and laser that can offer excellent gap adaptability, large penetration and moderate cooling rate [14-16]. 
Fig. 1 Typical cross-section view of the welded CP-Ti joint [9]

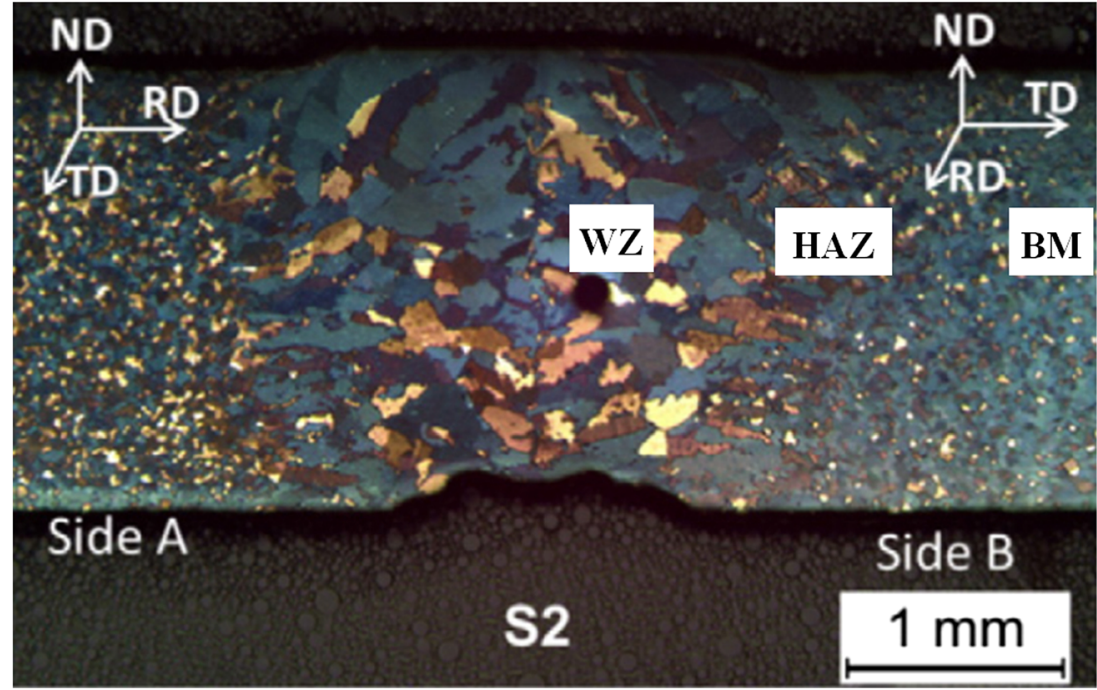

The strengthening mechanism of the welded CP-Ti joint is very complicated and still not fully understood yet despite significant research efforts have been made on this topic by many researchers previously. Figure 1 shows the crosssectional view of a typical CP-Ti weld [17]. It can be seen that the grain size of the weld zone (WZ) and heat affected zone (HAZ) in the joint is larger than that of the base metal (BM). According to the Hall-Petch relationship, as described in Eq. (1) below, a decrease in grain size usually leads to an increase in hardness and yield strength [18]:

$\sigma=\sigma_{0}+k_{0} d_{\text {grain }}^{-1 / 2}$

where $\sigma$ is the yield stress, $\sigma_{0}$ is the resistance to dislocation movement, $k_{0}$ is the hardening contribution from the grain boundary and $d_{\text {grain }}$ is the averaged grain size. However, most studies showed that the hardness and strength of the laser welded CP-Ti joints, which comprises of relatively larger grained WZ and HAZ zones, were higher than that of the BM, which consists of relatively smaller grains $[5,11,12,14,17]$. This is controversial to the Hall-Petch's law and stimulated plenty of research interests. A well-known theory was from H. Liu that the strengthen increased in the HAZ was due to the substructure strengthening effect while the WZ combines the substructure and the solute solution strengthening [19]. C. Li compared joints made by $1.5 \mathrm{~mm} \mathrm{CP-Ti}$ plates using laser and laser-MIG hybrid processes and pointed out that the interaction of cooling rate with the oxygen and nitrogen concentration played a significant role in the microhardness improvement [20]. M. Y. Wu obtained a sound thick CP-Ti joint by electron beam welding and found that the strengthening was mainly due to the suppression of prismatic slip in the WZ [5]. A. Karpagaraj studied the mechanical properties and microstructural characterization of automated TIG welding of thin CP-Ti sheets and suggested that the increase in weld metal strength was mainly due to the fine grained acicular $\alpha$ grains and solid-solution strengthening by TiCN in the WZ [21]. A study on linear friction welded CP-Ti by X.Y. Wang revealed that it was the grain orientation, rather than microstructure, actually affecting the microhardness distribution of the welded joint and a correlation between mechanical properties and texture was also pointed out [22].

Therefore, it can be seen in the literature that there is no general agreement on the strengthening mechanism of CP-Ti welds and further study is still needed. In this paper, a systematic investigation on laser and laser-arc hybrid welding of CP-Ti will be carried out and a comprehensive analysis of the strengthening in the joints will be conducted. The autogenously fiber laser beam welding and laser-MIG hybrid welding of CP-Ti will be performed and the mechanical properties, microstructure and texture of the joint will be characterized. A correlation between microstructure, texture distribution and mechanical properties will be attempted and the strengthening mechanisms in the two welding processes will be proposed as well. The influences of minor elements, such as oxygen and nitrogen, on the weld properties were not taken into account in this study.
Table 1 Chemical composition of the commercially pure titanium and the filler wire (wt.\%)

\begin{tabular}{lllllll}
\hline & $\mathrm{N}$ & $\mathrm{C}$ & $\mathrm{H}$ & $\mathrm{Fe}$ & $\mathrm{O}$ & $\mathrm{Ti}$ \\
\hline Commercial pure titanium & 0.030 & 0.080 & 0.015 & 0.300 & 0.250 & Balance \\
Filler wire (ERTA2ELI) & 0.015 & 0.030 & 0.008 & 0.120 & $0.08-0.16$ & Balance \\
\hline
\end{tabular}


Fig. 2 Experimental setups with trailing nozzles. a Laser beam welding. b Laser-MIG hybrid welding

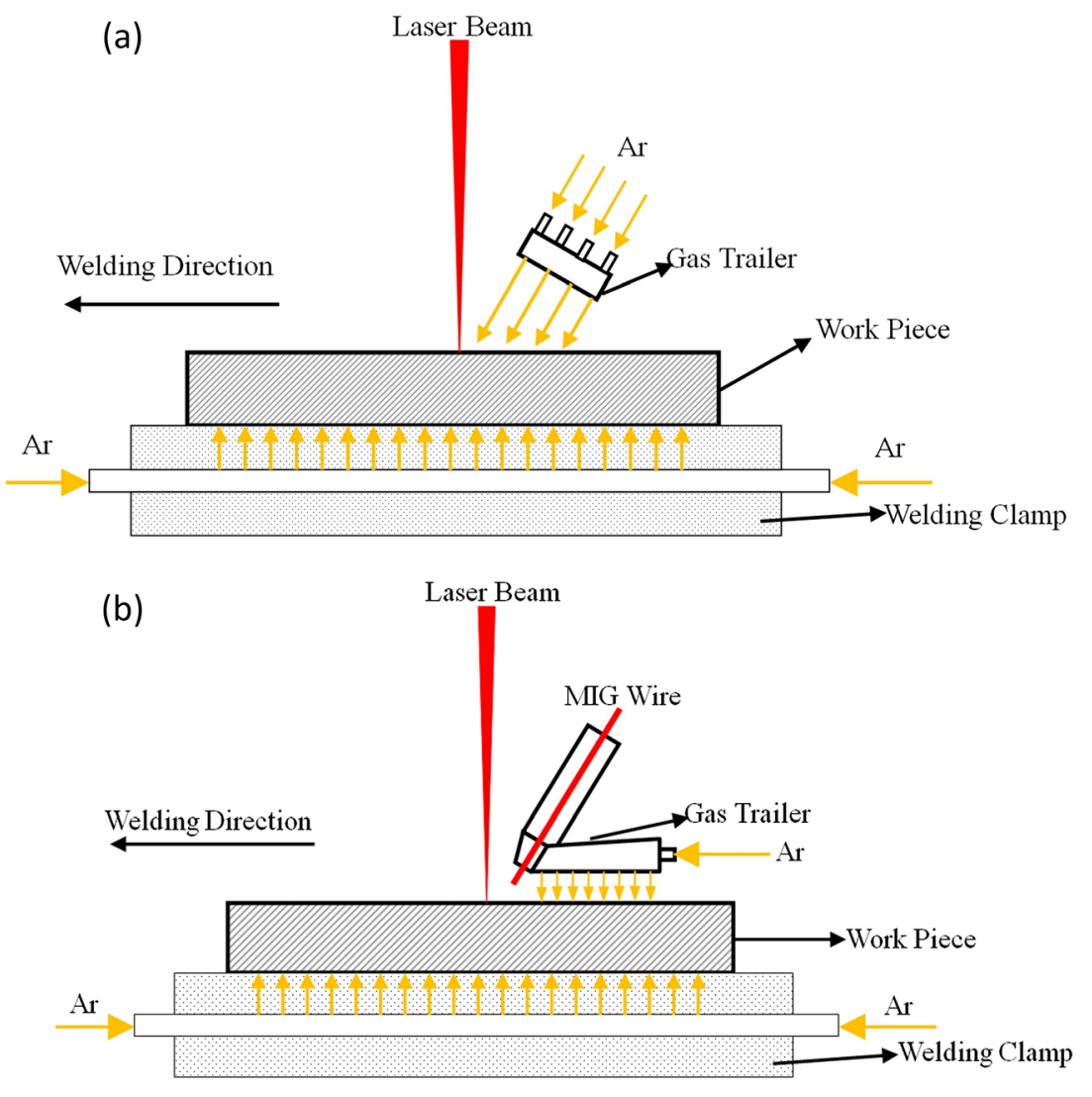

\section{Material and methods}

The base metal (BM) was grade 2 hot rolled commercially pure titanium plates in a dimension of $120 \mathrm{~mm} \times 60 \mathrm{~mm} \times$ $4.2 \mathrm{~mm}$. Autogenously laser beam and laser-MIG hybrid butt welding were carried out. ERTA2ELI filler wire with $1.0 \mathrm{~mm}$ diameter was used in the laser-MIG hybrid welding process. The chemical compositions of the base metal and the filler wire are given in Table 1.

A YLS-6000 IPG high-brightness multi-mode ytterbiumdoped (Yb-fiber) continuous wave (CW) laser system was employed for both laser beam and laser-MIG hybrid welding in this study. It operated at a wavelength of $1070 \pm 10 \mathrm{~nm}$ with a maximum power output of $6 \mathrm{~kW}$. A TPS-4000 Fronius welding machine was used for laser-MIG hybrid welding. Schematics of the laser beam welding process and laserMIG hybrid welding setups are depicted in Fig. 2. For laser beam welding, a trailing nozzle with four copper pipes were positioned behind the weld pool to deliver sufficient shielding gas (Fig. 2a). For laser-hybrid welding, a wider gas shielding zone was needed and therefore a trailing nozzle cluster covering an area of $120 \mathrm{~mm} \times 50 \mathrm{~mm}$ was attached to the back of the MIG welding torch, as shown in Fig. 2b, which can ensure adequate protection of the weld surface during welding.

The parameters for both welding processes are given in Table 2. These parameters were optimized results based on a large number of experiments that would produce defect-free weld, i.e. no lack of fusion, hot cracking, gas inclusion,
Table 2 Welding parameters for joining of commercially pure titanium plates

\begin{tabular}{lll}
\hline Parameters & Laser beam welding & Laser-MIG hybrid welding \\
\hline Laser power $(\mathrm{kW})$ & 3.5 & 2.5 \\
Welding speed $(\mathrm{mm} / \mathrm{s})$ & 20 & 10 \\
Defocusing $(\mathrm{mm})$ & 6 & 6 \\
Arc current $(\mathrm{A})$ & - & 100 \\
Arc voltage $(\mathrm{V})$ & - & 18.8 \\
Laser-arc distance $(\mathrm{mm})$ & - & 2 \\
Butt joint gap $(\mathrm{mm})$ & 0 & 0 \\
The face gas flow rate $(\mathrm{L} / \mathrm{min})$ & 50 & 50 \\
The back gas flow rate $(\mathrm{L} / \mathrm{min})$ & 20 & 20 \\
\hline
\end{tabular}




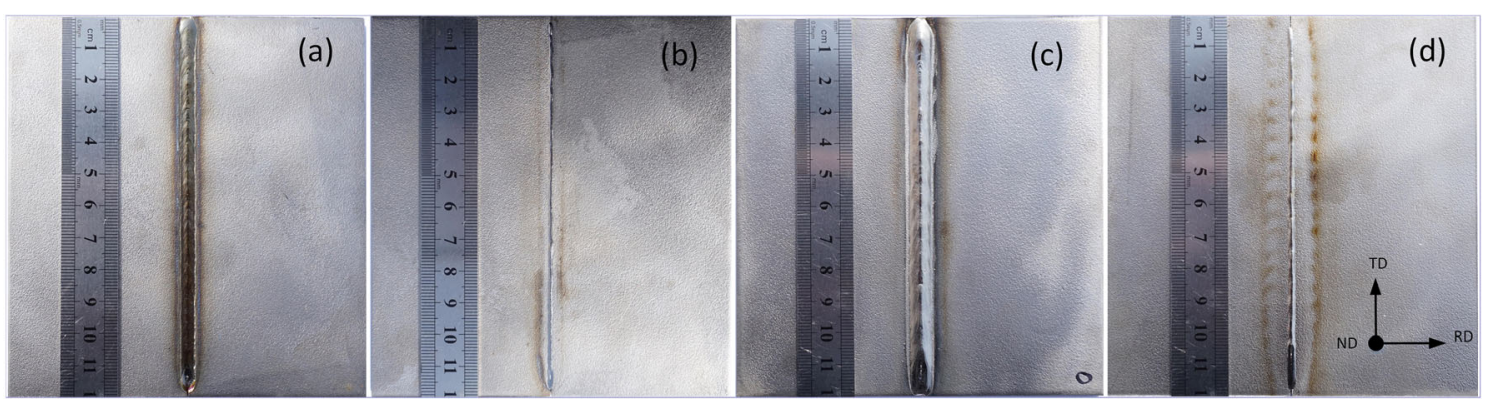

Fig. 3 Macrographs of the welded commercially pure titanium joints. Front (a) and reverse (b) side of laser beam weld. Front (c) and reverse (d) side of laser-MIG hybrid weld

undercut or oxidation etc. The current in Table 2 for MIG welding was consistent and the voltage was the corresponding value recorded during the process. The wire feeding was smooth and steady resulted in minimum spatter and appropriate reinforcement. In this study, RD denotes the rolling direction of the base plate, TD is the transverse direction perpendicular to the RD and ND is the normal direction vertical to the titanium plate surface.

The microstructure and texture of the two types of welds were analyzed with optical microscopy (OM), scanning electron microscope (SEM) and electron backscattered diffraction (EBSD). The EBSD data was processed by using Oxford Instruments HKL Channel 5 software to illustrate the textural information. Meanwhile, $\mathrm{X}$-ray diffraction (XRD) was used to identify the phases in welded zones. The X-ray diffraction was carried out in a Shimadzu XRD-6000 system with $40 \mathrm{kV}$ voltage, $\mathrm{Cu}$ target, scanning within $30^{\circ}-80^{\circ}$ range at $4 \% \mathrm{~min}$ speed and $0.02^{\circ}$ step size. The samples were firstly ground by using a series of $\mathrm{SiC}$ paper up to 4000 grit, polished using diamond paste down to $1 \mu \mathrm{m}$ and finished with OPS colloidal silica suspension to remove the mechanically deformed layer. For OM observations, the samples were etched for $50 \sim 60 \mathrm{~s}$ with Kroll's reagent $\left(5 \% \mathrm{HNO}_{3}, 5 \%\right.$ $\mathrm{HF}$ and $90 \% \mathrm{H}_{2} \mathrm{O}$ ) after grinding and polishing. To assess the efficiency of the joints, Vickers microhardness was measured at a load of $300 \mathrm{~g}$ with $10 \mathrm{~s}$ dwelling time by using a KB30S automated hardness tester. The hardness tests were carried out through three lines which were $1 \mathrm{~mm}, 2.1 \mathrm{~mm}$ and $3.2 \mathrm{~mm}$ away from the top surface, respectively, and the indents had $250 \mu \mathrm{m}$ interval along each line. The results were statistically averaged between three tests conducted on three different cross-sectional views of same specimen. The strength of the welds were examined by uniaxial tensile tests at room temperature with a $5 \mathrm{~mm} / \mathrm{min}$ speed on a SANS CMT5205 automated testing system. The experiments were set up according to ISO 4136:2012 "Destructive tests on welds in metallic materials - Transverse tensile test" and ISO 6892-1:2016 "Metallic materials - Tensile testing - Part 1: Method of test at room temperature." Finally, the fracture surfaces were investigated by SEM.
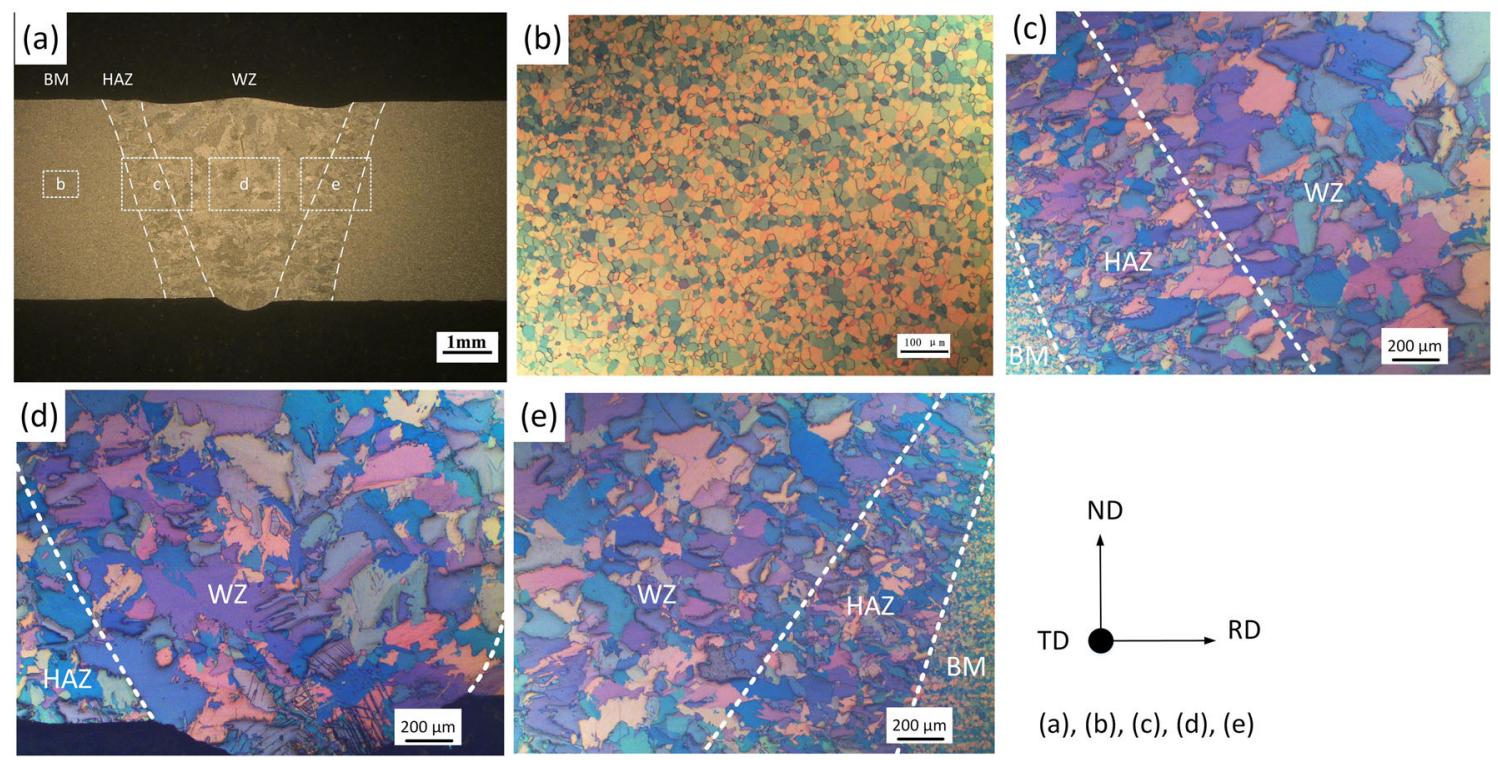

(a), (b), (c), (d), (e)

Fig. 4 Microstructure of the welded plate with laser beam welding. a An overview. b BM. c Left HAZ. d WZ (C: large columnar $\alpha$ grain, S: serrated $\alpha$ grain, A: acicular $\alpha$ grains). e Right HAZ 

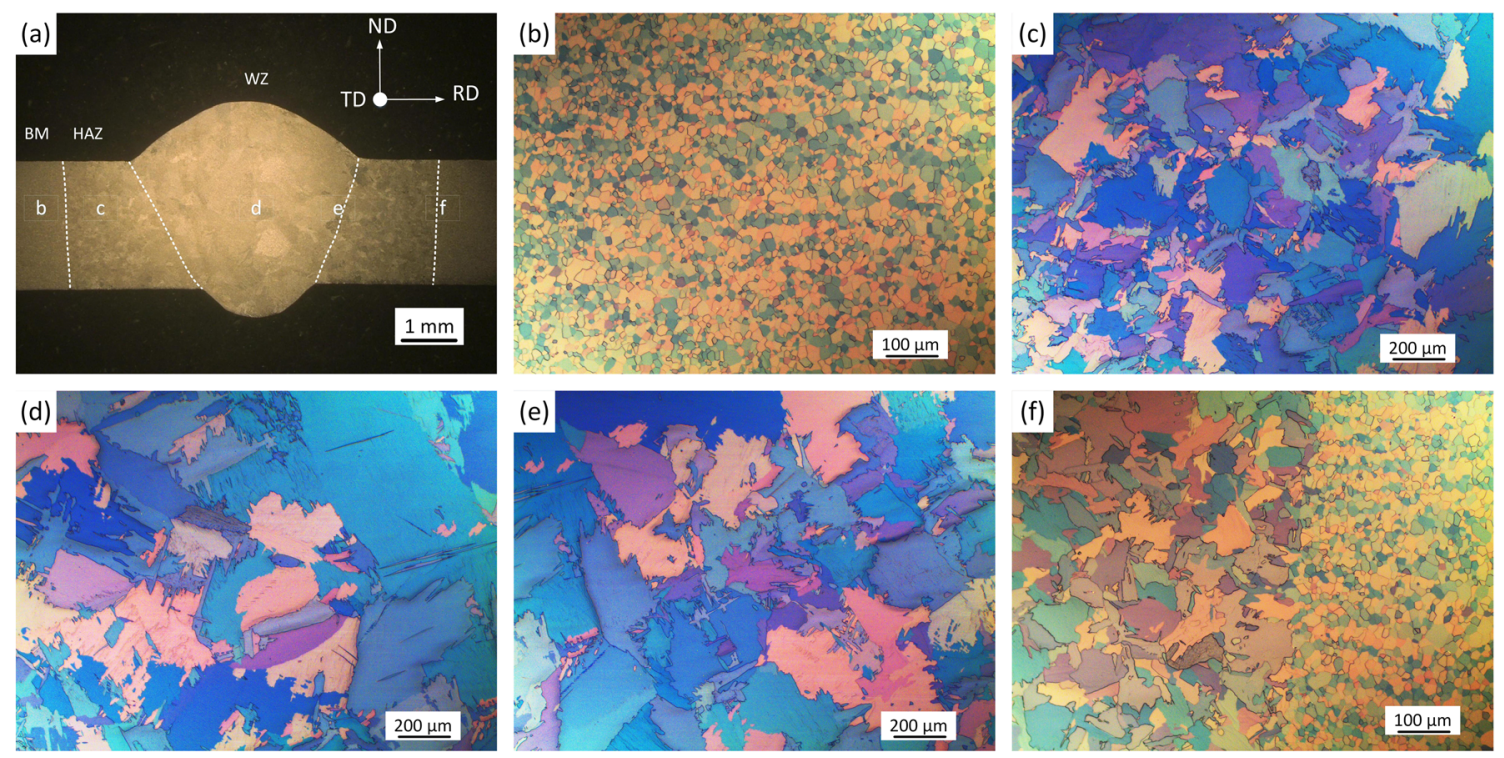

Fig. 5 Microstructure of the welded plate with laser-MIG hybrid welding. a An overview. b BM. c Left HAZ. d WZ. e Near fusion line. f Right HAZ

\section{Results and discussion}

\subsection{Macro- and microstructure}

The macrographs of the laser beam and laser-MIG hybrid welded CP-Ti butt joints are shown in Fig. 3. Spatter-free, uniform and silvery white colored weld beads were observed in all specimens which indicated an excellent shielding effect of the trailing nozzle setup for both welding processes.

Figure 4a shows a low-magnification macrograph of the cross-sectional view of laser beam welded joint after etching. The WZ exhibits a typical "V" shape and no porosity or other defects was visible at this scale. A clear boundary can be drawn between the BM and HAZ, but the fusion line can hardly be distinguished between the HAZ and WZ from the microstructural point of view. However, an estimated fusion line can be drawn between the weld toe and root, as the dotted lines indicated in Fig. 4a. Hence, a narrow HAZ with an averaged width of approximate $0.71 \mathrm{~mm}$ can be extracted on the crosssectional view. Figure $4 \mathrm{~b}-\mathrm{e}$ illustrates the grain structure of laser beam weld revealed under polarized light. An equiaxed grain structure could be found in BM, as shown in Fig. 4b, while a mixture of large columnar, irregular serrated and acicular $\alpha$ grains were observed in WZ (Fig. 4d). Elongated grains perpendicular to the fusion line, which was formed by preferential growth along the thermal gradient direction, could be found in both left and right HAZ zones, as shown in Fig. 4c, e. The HAZ also contains finer serrated $\alpha$ grains indicating a higher cooling rate than WZ.

The cross-sectional view of laser-MIG hybrid welded CP-Ti joint is shown in Fig. 5. No pores, cracks or undercuts defects were found in the weld zone. The laser-MIG hybrid weld has relatively wider HAZ, i.e. approximate $2.90 \mathrm{~mm}$, due to the larger heat input. As shown in Fig. $5 \mathrm{~d}$, the WZ consists of coarse columnar $\alpha$ grains, irregularly jagged $\alpha$ grains, and a small amount of relatively finer equiaxed $\alpha$ grains. Unlike the laser beam welding situation, almost no needle-like $\alpha$ grain structure was spotted in WZ of laser-MIG hybrid circumstance. This can be explained that the laser-MIG hybrid welding has a larger heat input and slower solidification speed comparing with laser beam welding, so that the needle-like $\alpha$ grain nuclei have more time to grow and coarsen thereafter. In addition, as seen in Fig. $5 \mathrm{~d}-\mathrm{f}$, the HAZ features coarser grains than that of the laser beam welded joint.
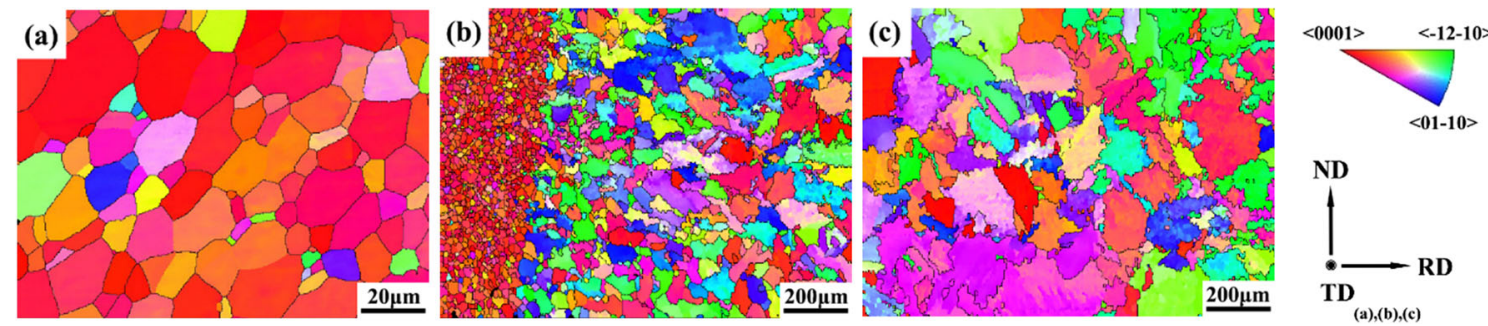

Fig. 6 EBSD inverse pole figure maps showing the microstructure of the different zones of laser beam welded joint. a BM. b HAZ. c WZ 

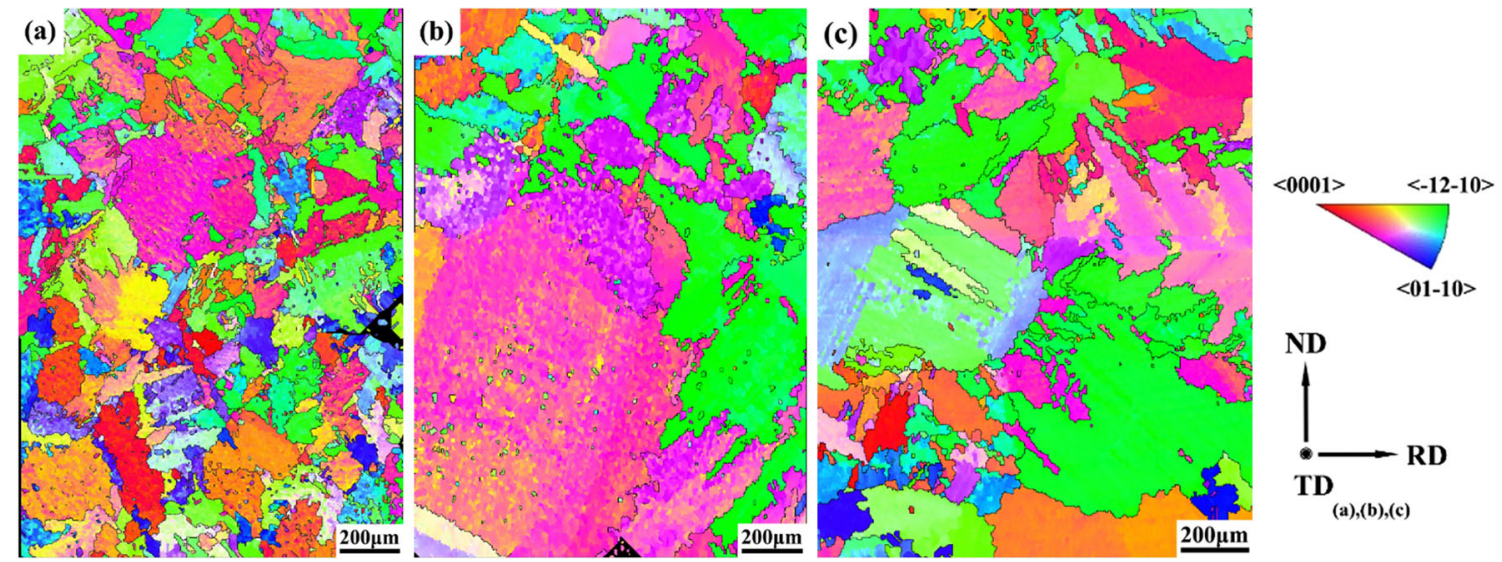

Fig. 7 EBSD inverse pole figure maps showing the microstructure of the different zones of laser-MIG hybrid welded joint. a HAZ close to BM. b HAZ close to WZ. c WZ

\subsection{EBSD analysis}

The crystalline orientation colored map at different regions of laser beam welded joint is shown in Fig. 6. It can be seen that the $<0001>$ orientation of the majority of the grains in $\mathrm{BM}$ are aligned along the TD direction indicating a strong texture (Fig. 6a). In comparison, the orientations of the grains in the HAZ and WZ are randomly mixed, as shown in Fig. 6b, c, respectively.

Figure 7 illustrates the crystallographic orientation colored map at different regions of laser-MIG hybrid welded joint. It shows that all the HAZ and WZ regions consist of a mixture of acicular and large grains with a randomly distributed orientation. Unlike the base material, no obvious texture can be observed in the HAZ and WZ regions. However, the colored maps indicate a grain coarsening effect from HAZ to WZ, as shown in Fig. 7a-c.

Figure 8 shows the inverse pole figure corresponding to three regions of the laser beam welded joint as shown in
Fig. 5. In Fig. 8a, it can be found that in the BM, the direction of $<0001>$ is parallel to ND while the direction of $<01 \overline{1} 0>$ is nearly parallel to TD, which has a maximum polar density of 7.05 along the ND. This is a typical characteristic of bimodal texture that is usually obtained in hot rolled titanium [23]. In Fig. $8 b$, c, the textures were significantly weakened in the $\mathrm{HAZ}$ and $\mathrm{WZ}$ after the laser beam welding process. In HAZ, the maximum polar density is 2.51 and only a few grains with the direction of $<0001>$ parallel to RD can be spotted. In WZ, the maximum polar density is 3.52 and some grains with the direction of $<0001>$ parallel to the ND are present.

Figure 9 illustrates the inverse pole figure corresponding to different regions of the laser-MIG hybrid welded joint shown in Fig. 7. The inverse pole diagram of the BM of the hybrid welding, as shown in Fig. 9a, is the same as that of laser beam welded joint. At the HAZ close to BM, the maximum polar density is 2.24 and there is no obvious texture. The orientation of grains between the $<0001>$ and $<0$
Fig. 8 Inverse pole figure maps for the different regions of laser beam welded joint. a BM. b HAZ. c WZ

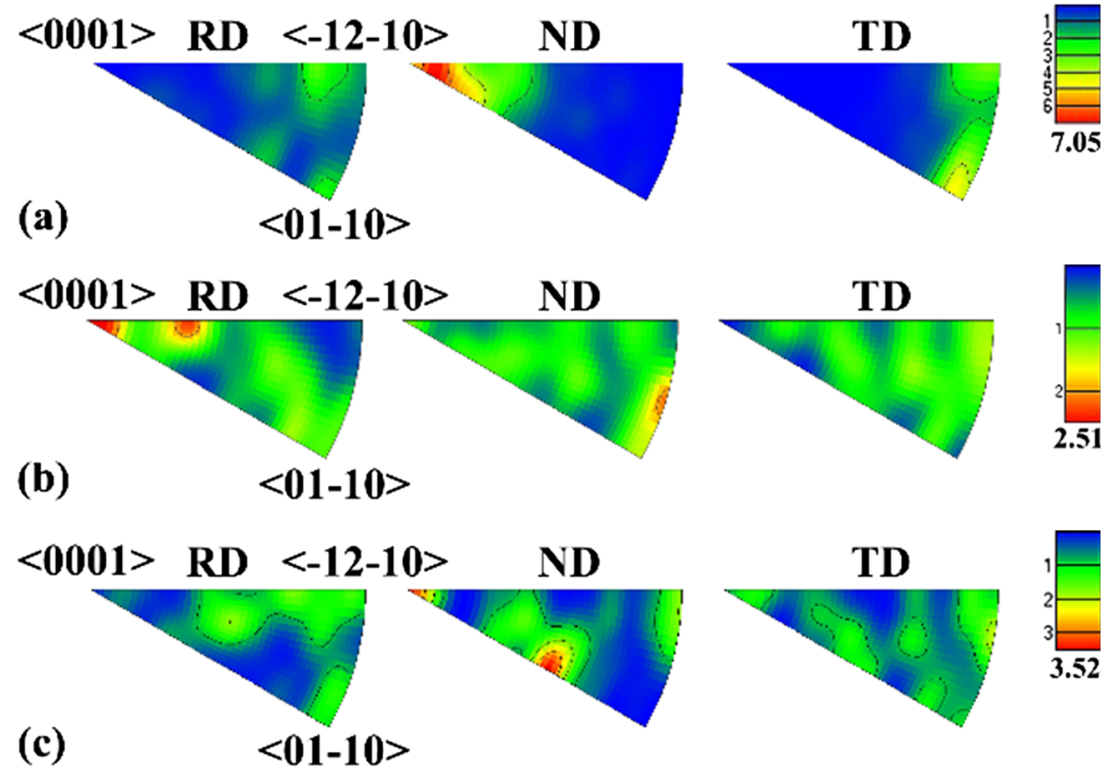


Fig. 9 Inverse pole figure maps for the different zones of laserMIG hybrid welded joint. a HAZ close to base metal. b HAZ close to weld zone. c Weld zone

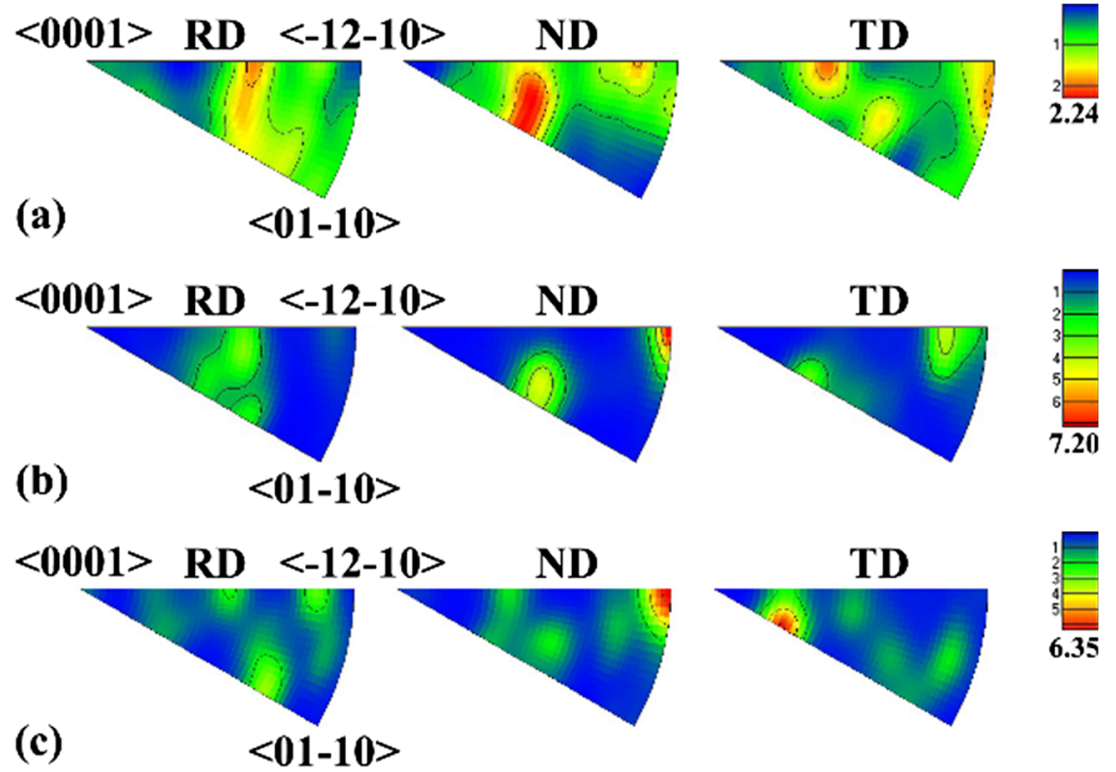

$1 \overline{10}>$ is parallel to the ND, as shown in Fig. 9a. However, in Fig. 9b, the maximum density of HAZ close to weld zone increased to 7.20 and the majority of the grains $<\overline{12} \overline{1} 0>$ orientation is parallel to the ND. In Fig. 9c, the inverse pole figure of the WZ indicates a maximum density value of 6.35. The $<\overline{1} 2 \overline{1} 0>$ orientations of the majority of the grains align with the ND direction and the grains between $<0001>$ and $\langle 01 \overline{1} 0\rangle$ are also parallel to the ND. These findings agree well with that in Fig. 7. In addition, for CPTi, previous studies have shown that the plastic deformation in ND will be more difficult to occur than in other directions, leading to a higher microhardness value [22].

In order to identify twin grains in the two types of welded joints, the grain boundaries were outlined on the EBSD maps by the Tango package in Channel 5, as shown in Figs. 10 and 11. It is known that in the coarse $\alpha$ phase, there are mainly $\{11 \overline{2} 2\}$ compressive twins and $\{10 \overline{1} 2\} /\{11 \overline{2} 1\}$ tensile twins. Thus, the high-angle grain boundaries $\left(>15^{\circ}\right)$ are outlined in black, whereas the grain boundaries of $\{10 \overline{1} 2\}$ and $\{11 \overline{2} 2\}$ twins observed in this study are outlined in red and blue, respectively. Figure 10 indicates that there are a large number of twin grains formed after the laser beam welding process due to the large welding residual stress in the joint. In Fig. 11, it can be found that an extremely high concentration of $\{10 \overline{1} 2\}$ tensile twins occurred in the HAZ close to BM in the laser-MIG hybrid welded joint. It has been known that the formation of twin grains will change the mechanical performance of the joints resulting in a hardening process [24, 25]. In addition, the introduction of twin boundaries can reduce the free path for dislocation to move, which in turn leads to an improvement in joint strength [26, 27].

The grain size, with and without twin grains in consideration, in different regions of the laser beam welded and laserMIG hybrid welded joints are calculated in Table 3. The average grain diameter of the $\mathrm{WZ}$ is significantly larger than that of the BM and the HAZ in the laser beam welded joints. It is noted that the average grain size at WZ reaches $41.11 \mu \mathrm{m}$ without counting twin grains. For hybrid welded joints, the average grain size excluding twin grains in the WZ is $50.13 \mu \mathrm{m}$, which is larger than that of laser beam welded joint, due to a higher thermal input from the laser and arc heating. As listed in Table 3, in the two welding situations, the averaged grain size was significantly reduced when twin grains were included in the statistics. According to Hall-Petch equation, i.e. the yield strength is reversely proportional to the
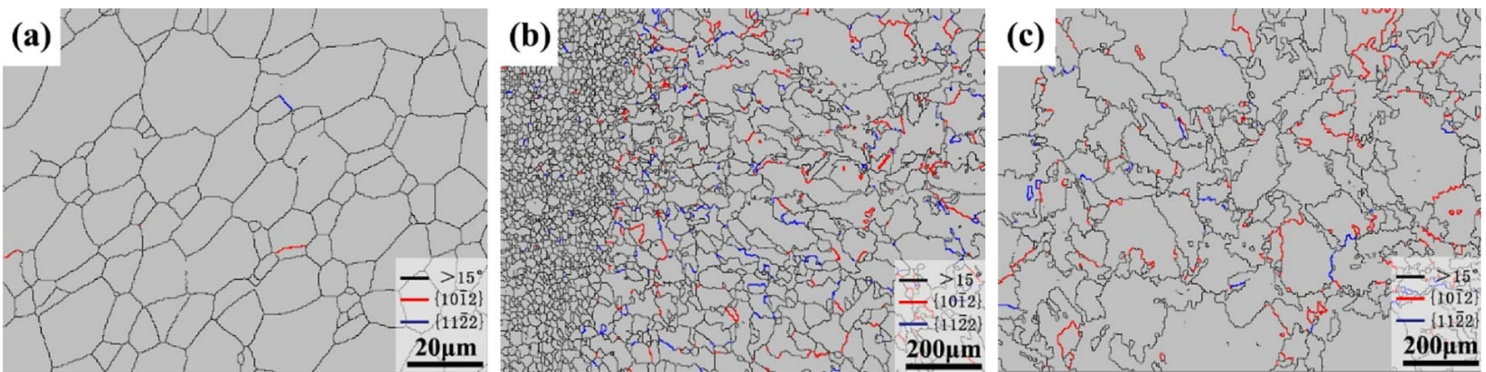

Fig. 10 Grain boundary maps of the different zones of laser beam welded joint. a BM. b HAZ. c WZ 

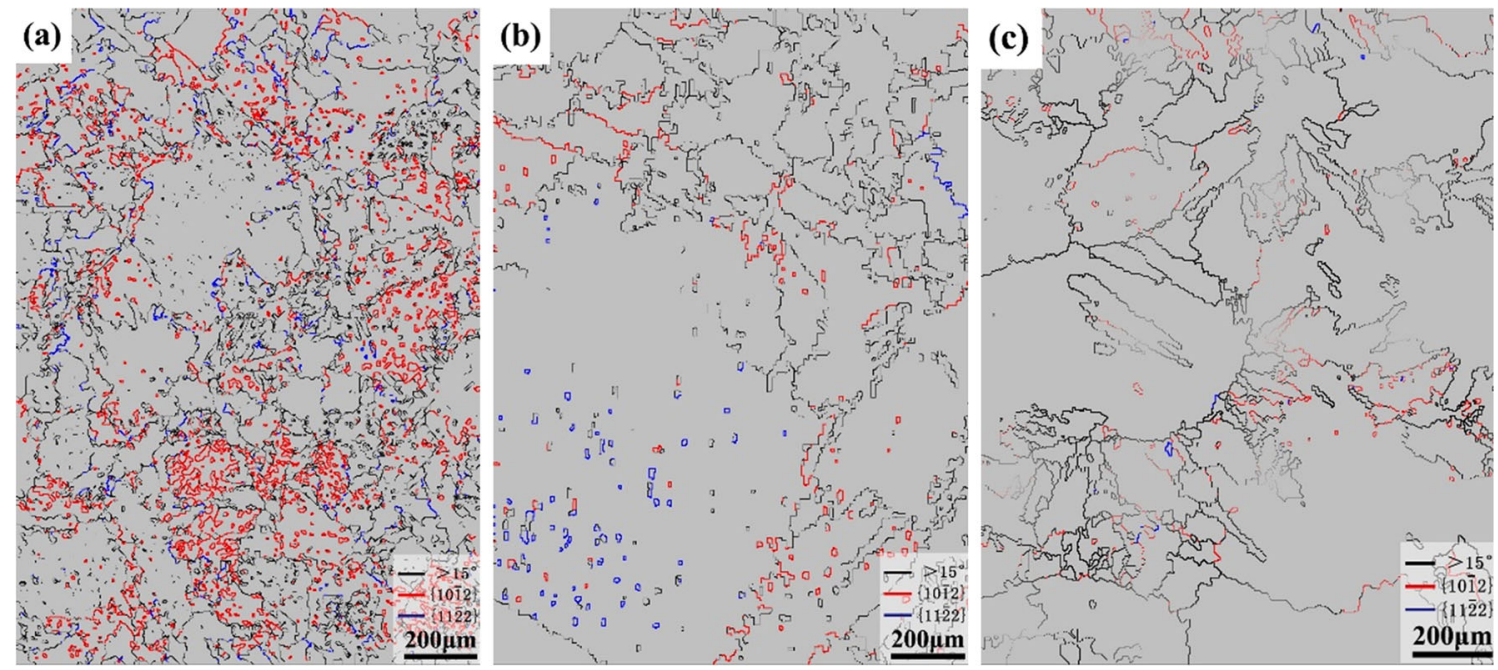

Fig. 11 Grain boundary maps of the different zones of laser-MIG hybrid welded joint. a HAZ close to BM. b HAZ close to WZ. $\mathbf{c}$ WZ

Table 3 Average grain diameter D $(\mu \mathrm{m})$ at different regions of the laser beam welded and laser-MIG hybrid welded joints

\begin{tabular}{lllll}
\hline Laser beam welding & Regions & BM & HAZ & WZ \\
& Average grain diameters (twins excluded in the statistics) & 12.07 & 41.11 \\
& Average grain diameters (twins included in the statistics) & 11.98 & 19.78 & 12.66 \\
Laser-MIG hybrid welding & HAZ close to BM & HAZ close to WZ & WZ \\
& Regions & 49.28 \\
& Average grain diameters (twins excluded in the statistics) & 45.62 & 55.34 & 38.24 \\
& Average grain diameters (twins included in the statistics) & 20.24 & 35.67 \\
\hline
\end{tabular}

grain size, therefore, the formation of twins will improve the strength of the welded joint.

Slip is one of the major deformation modes in the plastic deformation process of pure titanium, including $\{10 \overline{1} 0\}<1$ $\overline{2} 10>$ prismatic slip (dominates), $\{0002\}<11 \overline{2} 0>$ basal slip, $\{10 \overline{1} 2\}<1 \overline{2} 10>$ and $\{10 \overline{1} 1\}<1 \overline{2} 10>$ pyramidal plane slip [28, 29]. For the welded titanium plates, residual strain always exists due to the non-uniform heating and cooling. The energy accumulated from the strain would act as the driving force during the slip deformation process, directing the grain towards a preferred rotation and movement following the Schmid's law. In this study, the Schmid factor distributions and the averaged value in the two types of joints are shown in Figs. 12 and 13.

The average Schmid factor for BM, WZ and HAZ in the laser beam welded joint were $0.37,0.33$, and 0.32 , respectively (Fig. 12). Figure 13 shows that the average Schmid factor for the HAZ close to BM, HAZ close to WZ, and WZ in laser-

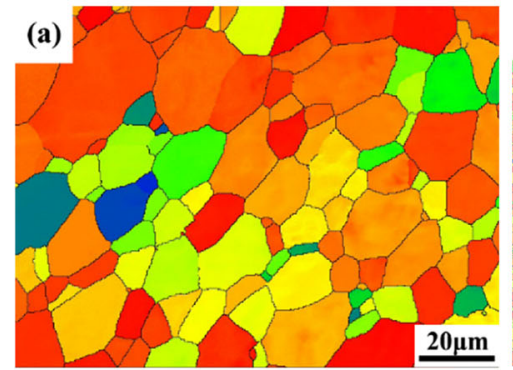

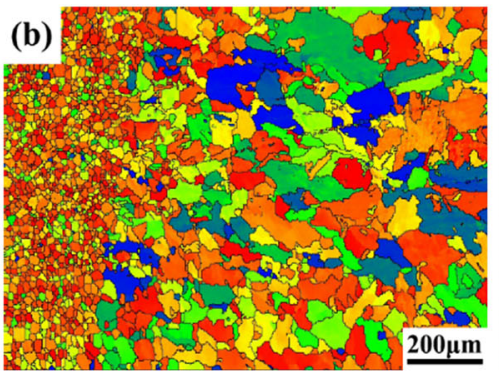

(a) Average Schmid Factor: 0.37

(b) Average Schmid Factor: 0.32

\section{(c) Average Schmid Factor: 0.33}

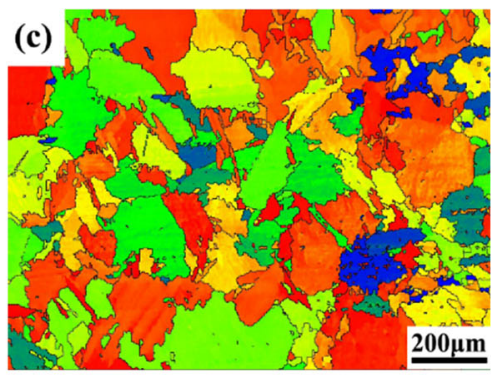

$\mathrm{SF}=\mathbf{0} \longrightarrow \mathrm{SF}=0.5$

Fig. 12 Schmid factor maps for the different zones of laser beam welded joint for prismatic slip under tensile stress along the RD. a BM. b HAZ. c WZ 


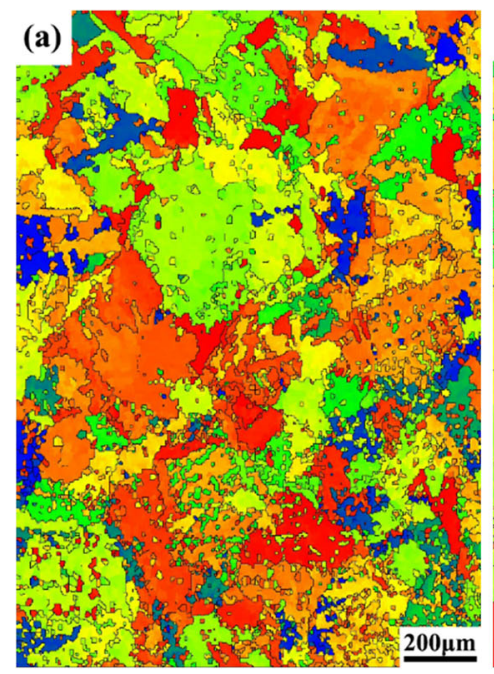

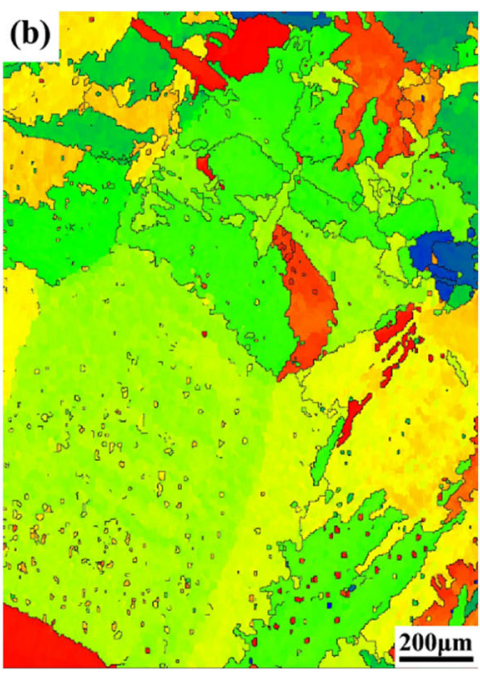

(a) Average Schmid Factor: 0.32

(b) Average Schmid Factor: 0.27

(c) Average Schmid Factor: 0.34
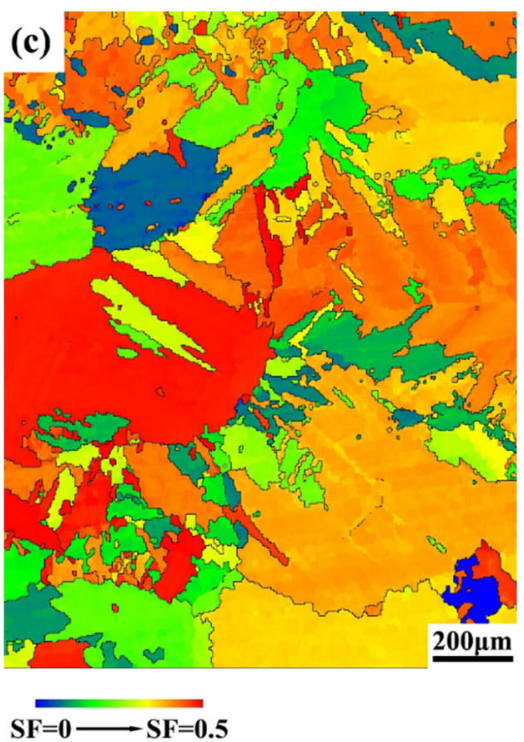

Fig. 13 Schmid factor maps for the different zones of laser-MIG hybrid welded joint for prismatic slip under tensile stress along the RD. a HAZ close to BM. b HAZ close to WZ. c WZ

MIG hybrid welded joint were $0.32,0.27,0.34$, respectively. The above Schmid factor analysis indicated that the average Schmid factor of the prismatic slip was the highest $(0.37)$ for BM in the two types of joints. It is known that large Schmid factor always promote deformation, due to the migration of grain boundary and grain rotation. The higher the Schmid factor, the easier it is to slip in the slip system obeying the Schmid's law [30, 31]. So, it can be deduced that the grain boundary sliding will take place firstly at BM during slip deformation for both joints. Therefore, although the BM has smaller grain size, which is supposed to have higher strength according to the Hall-Petch's law, the higher tendency of deformation under load compromises the grain size strengthening effect and results in relatively weaker BM comparing with the coarsened HAZ and WZ.

\subsection{X-ray diffraction}

$\mathrm{X}$-ray diffraction analysis in the $\mathrm{BM}$ and $\mathrm{WZ}$ of the two types of joints was carried out and the results are depicted in Fig. 14 by comparing with the PDF standard peaks of Ti (ICDD: 441294). The intensity ratios of crystallographic planes of base metal, laser beam and laser-MIG welds related to matrix are listed in Table 4. The diffraction peaks are all hexagonal $\alpha$ phase in $\mathrm{BM}$ and the $\mathrm{WZ}$ of the two types of joints. The grains in the $\mathrm{WZ}$ of the laser beam welded joint have stronger diffraction peaks and smaller

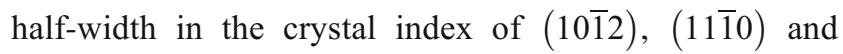
$(10 \overline{1} 3)$ indicating a coarser grain size. Meanwhile, the diffraction peaks of the laser-MIG hybrid welds slightly shifted to the right, suggesting that there was a considerable extent of internal stress or lattice distortion in the joint [32]. This large stress or lattice distortion can be related to the formation of twins in the welded joints. Furthermore, the smaller half-width indicates the formation of much larger grains in the hybrid welded joint.

\subsection{Microhardness}

Figure 15 shows the microhardness distribution in the two types of titanium welds. The hardness testing of "top" and "bottom" were carried out with traverses at

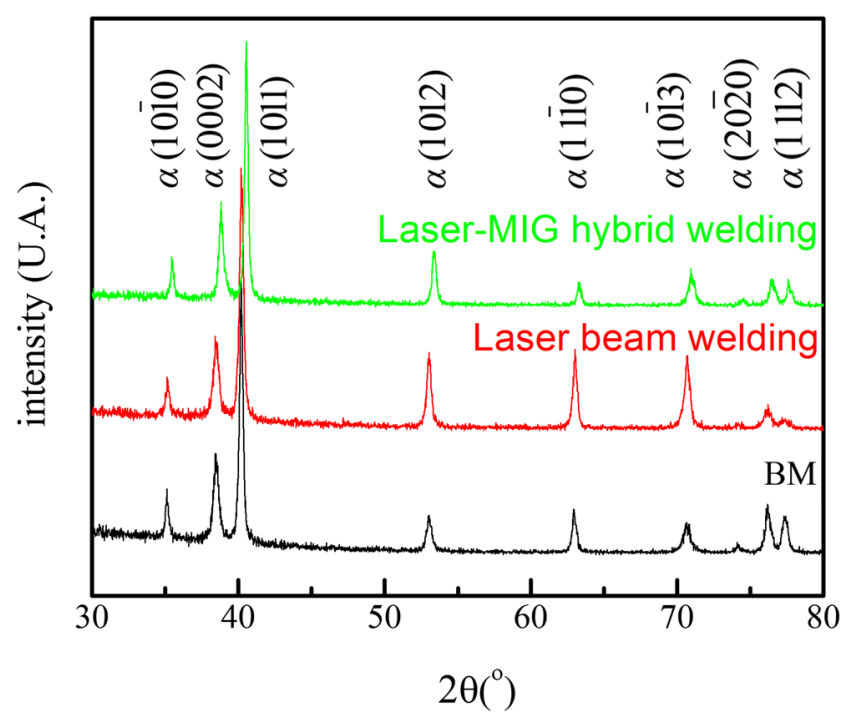

Fig. $14 \mathrm{X}$-ray diffraction spectrums of the base metal and the welded zones of the welds 
Table 4 The intensity ratios of crystallographic planes in base metal, laser beam, and laser-MIG hybrid welds

\begin{tabular}{|c|c|c|c|c|c|c|c|c|}
\hline & $10 \overline{1} 0$ & 0002 & 1011 & 1012 & $11 \overline{1} 0$ & $10 \overline{1} 3$ & $20 \overline{2} 0$ & 1112 \\
\hline BM & $15.9 \%$ & $30.9 \%$ & $100 \%$ & $12.8 \%$ & $17.9 \%$ & $11.4 \%$ & $19.3 \%$ & $13.0 \%$ \\
\hline Laser & $16.7 \%$ & $35.4 \%$ & $100 \%$ & $22.7 \%$ & $8.7 \%$ & $12.5 \%$ & $10 \%$ & $10 \%$ \\
\hline Hybrid & $15.9 \%$ & $28.4 \%$ & $100 \%$ & $31 \%$ & $33.9 \%$ & $33.2 \%$ & $7.5 \%$ & $3.4 \%$ \\
\hline
\end{tabular}

$1 \mathrm{~mm}$ below the top surface and over the bottom surface of the plate respectively where the "middle" is at the half thickness of the plate. Because the joint can be seen as symmetric, for simplicity, only the data on the right half

\section{(a) Laser beam weld joint}

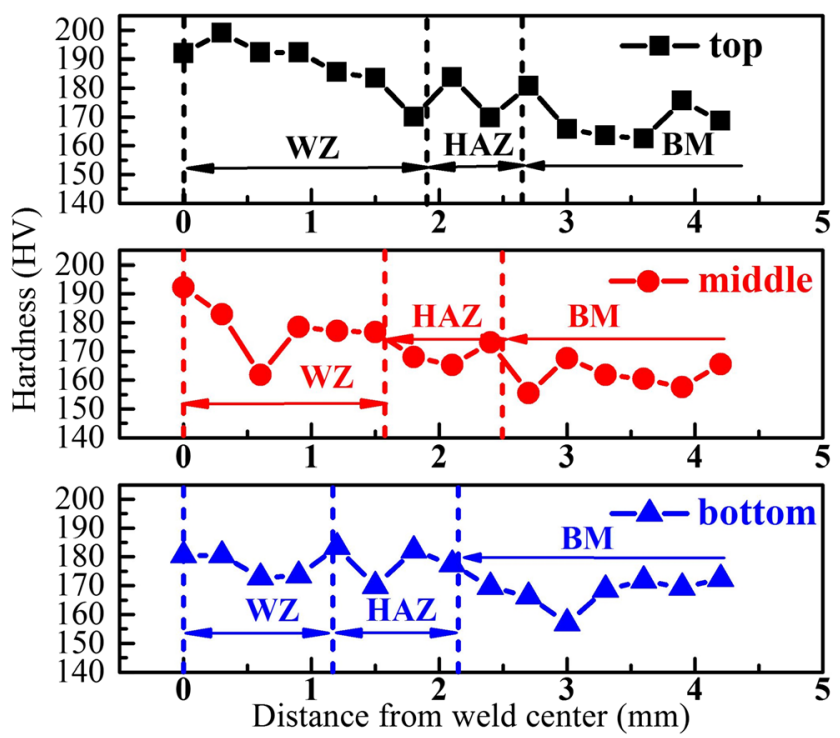

(b) Laser-MIG hybrid weld joint

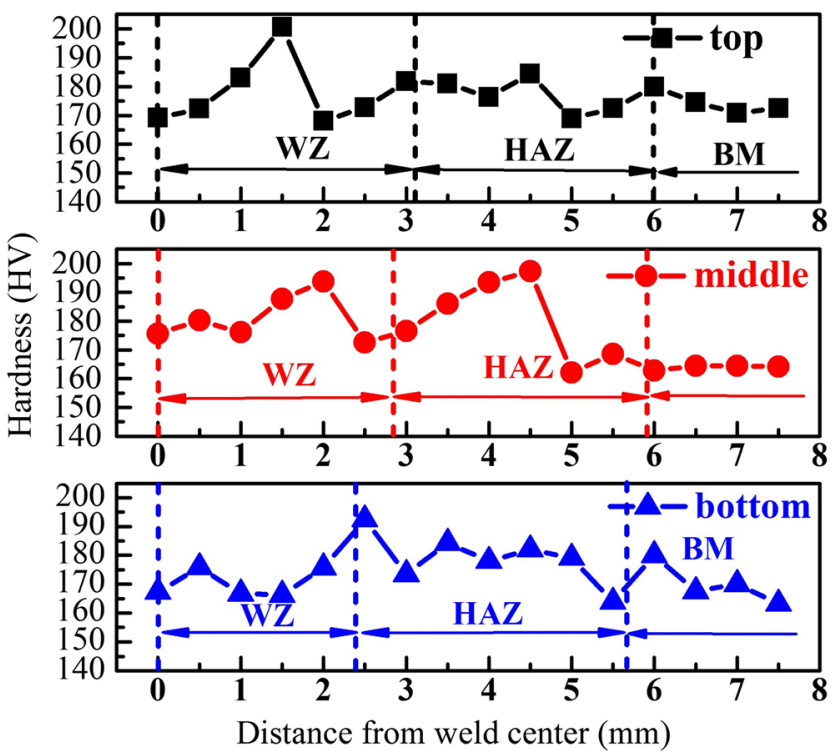

Fig. 15 Microhardness profiles on TD-RD cross-section of the welded joint. a Laser beam welded joint. b Laser-MIG hybrid welded joint is plotted here. Figure 15a indicates that the peak microhardness occurs in the $\mathrm{WZ}$ and successively decreases towards HAZ and BM of the laser beam welded joint. Similarly, in the laser-MIG hybrid welded joint, the microhardness of the WZ and the HAZ are also both higher than that of BM. This can be attributed to the formation of the twin gains in WZ and HAZ in both welds. It should be noted that the microhardness exhibits a fluctuate distribution in the WZ and HAZ due to the significant difference in the grain size in different sub-regions. In addition, the laser-MIG hybrid joint features a larger fluctuation of microhardness in WZ than that of the laser beam welded joint, which agrees well with the different distribution of twin grains demonstrated in Figs. 10 and 11. In other words, the twin grains may play a more important role in the laser-MIG hybrid joint strengthening than that in the laser beam welded joint.

\subsection{Tensile strength and fracture morphology}

Tensile tests of both weld samples and base metal were carried out at $5 \mathrm{~mm} / \mathrm{min}$ testing rate and the fractured specimens are shown in Fig. 16. As shown in Fig. 16a, the fracture position of the BM samples was near the centerline. However, as shown in Fig. 16b, c, the fracture positions of the two types of welded samples were all in the $\mathrm{BM}$ zone indicating the base metal was the weak point of the joints.

Due to a failure of equipment and limited access of resources, it was unable to use an extensometer during the tensile tests. Therefore, Fig. 17 plots the loaddisplacement curves of the two types of welded samples and BM samples. The tensile strength and strain were worked out by dividing the load with cross-sectional area and comparing the overall length before and after tests. However, it should be noted that the calculation may not be accurate because of the necking phenomena and human error, but it is comparable between specimens tested under same conditions. The calculations are summarized in Table 5 and it can be seen that the averaged tensile strength of the laser beam welded joint and the laserMIG hybrid welded joint were $421.4 \mathrm{MPa}$ and $432.6 \mathrm{MPa}$, respectively, which were both higher than the $\mathrm{BM}$ only situation $(410 \mathrm{MPa})$, while the two average elongations (44\% and $40 \%$ ) were lower than the BM only 

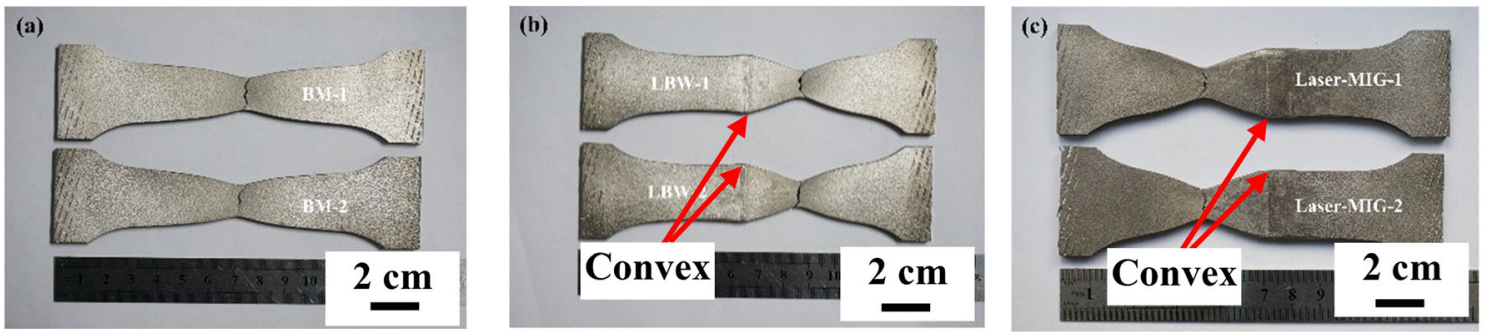

Fig. 16 Macrographs of the fractured samples after the tensile tests. a The base metal samples. b Laser beam welded samples. c Laser-MIG hybrid welded samples

situation $(47.5 \%)$. The increase in the tensile strength of two welds is due to the reinforced weld zones in the presence of large number of twin grains. However, improvement on the strength of the welds slightly compromised the ductility resulting in relatively lower elongations. In addition, it should be noted that the MIG-laser weld zone has excessive material brought in by the filler wire that may also contribute to the increase of strength [33].

Compared with BM samples, the stress in the laserMIG hybrid welded joint samples reached the maximum value faster, and then the sample fractured with a relatively smaller strain, as shown in the enlarged upper-left corner figure in Fig. 17. This is due to that, as previously reported in literature $[34,35]$, the twin boundaries can lead to strain hardening in titanium and generally contribute to the slight decrease in the strain. In addition, the MIG-laser weld zone had excessive material that limited the ability of deformation during tensile tests and therefore resulted in a relatively small strain. One can also calculate the absorbed energy during tensile tests that can provide additional information about how the welds deform. The amount of energy that a weld can absorb before final fracture can be obtained

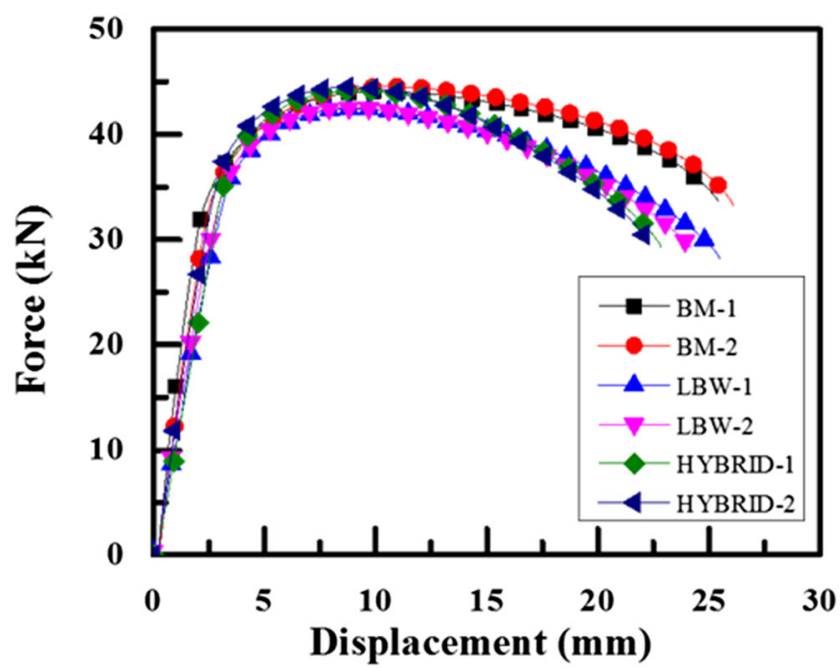

Fig. 17 Tensile curves of laser beam welded samples (LBM) and laserMIG hybrid welded samples (HYBRID) and BM samples by measuring the area underneath the stress-strain curve [36, 37]. However, based on Fig. 17, the difference of absorbed energy between the laser beam and laser-MIG hybrid weld specimens was trivial. Moreover, the fractured samples showed evident convex shapes in $\mathrm{WZ}$ and $\mathrm{HAZ}$ of the welded samples, as shown in Fig. 16. Although there are also some twin boundaries in the laser beam welded joint, the strain hardening phenomenon is not so obvious due to its narrower width of WZ and HAZ, as shown in Fig. 4.

Figure 18 shows the fracture surface morphology of base metal and both welds tensile specimens. Large number of dimples on the fracture surfaces indicates that all samples are subjected to plastic deformation prior to failure. By combing the large strain shown in Fig. 17, it can be concluded that the failure of BM and the two types of welded joint were all due to ductile fracture.

In summary, both laser beam and laser-MIG hybrid welded joints exhibited reinforced weld zone resulted in higher tensile strength of the overall joints. However, different strengthening mechanisms can be drawn from the microstructure and texture analysis in this study. For the laser beam welded joint, on the one hand, the grain size is relatively finer and some acicular type $\alpha$ grains can be formed due to its high cooling rate in the weld zone; on the other hand, the formation of twin grains reduces the average grain size and prevents the generation and movement of dislocations including slipping during plastic deformation. For the laser-MIG hybrid joint, firstly, twined grains played a significant role in the strengthening of the

Table 5 Calculated tensile mechanical properties of the welded joints and $\mathrm{BM}$

\begin{tabular}{llll}
\hline Condition & Tensile strength/MPa & $\begin{array}{l}\text { Elongation/ } \\
\%\end{array}$ & Fracture position \\
\hline LBW-1 & 412.05 & 45.0 & Base metal \\
LBW-2 & 412.75 & 43.0 & Base metal \\
Laser-MIG-1 & 431.00 & 40.0 & Base metal \\
Laser-MIG-2 & 434.20 & 40.0 & Base metal \\
BM-1 & 408.00 & 47.5 & Centerline \\
BM-2 & 412.00 & 47.5 & Centerline \\
\hline
\end{tabular}



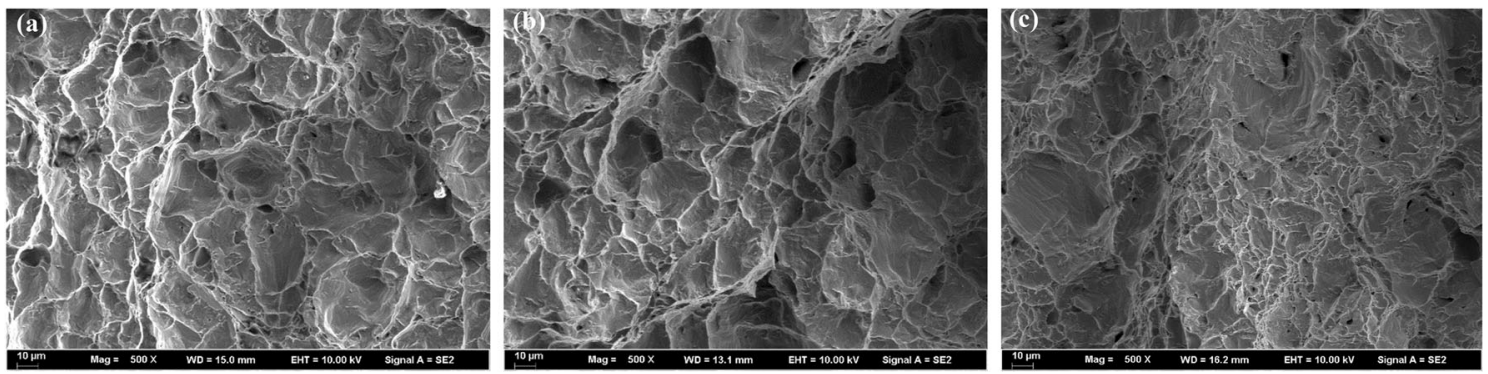

Fig. 18 Fracture surface morphology of the tensile samples. a BM. b Laser beam welded sample. c Laser-MIG hybrid welded sample

joint due to its higher concentration in the HAZ and weld zone; secondly, the texture along the ND direction in HAZ and WZ can further contribute to the increase in hardness. In addition, for both types of welded joints, the grains in BM feature a larger Schmid factor than that of WZ and HAZ so that the BM is easier to slip under tension. Consequently, all the fracture positions were found in the BM during tensile tests.

\section{Conclusions}

In this study, autogenously laser beam welding and laserMIG hybrid welding of CP-Ti were carried out and the microstructure, texture and mechanical properties of both joints were investigated to further understand the strengthening mechanisms in the welds. Both welding processes can produce high quality, defect-free joints. It was found that the heat affected zone (HAZ) and the weld zone (WZ) contain very complicated microstructure which typically is a mixture of coarsened and elongated $\alpha$ grains, acicular $\alpha$ phase and twined grains in both welded joints. A high concentration of $\{10 \overline{1} 2\}$ and $\{11 \overline{2} 2\}$ twin boundaries was found in the HAZ and $\mathrm{WZ}$ of the laser-MIG hybrid welded joint. The average Schmid factor for base metal (BM) showed a higher value than that of the WZ and HAZ in the welded joints. Greater microhardness was observed in WZ and HAZ and the laser beam welded joints featured a higher tensile strength. For the laser beam welded joints, the strengthening effect could be attributed to the formation of relatively smaller grains, acicular $\alpha$ grains and twined grains. In contrary, in the laser-MIG hybrid welded joint, the strengthening effect could be attributed to the formation of a higher concentration of twined grains and its typical grain texture along with ND in the HAZ and WZ.

Acknowledgements The authors acknowledge the financial support provided by the National Natural Science Foundation of China (Grant No. 51405206) and the China Postdoctoral Science Foundation (Grant No. 2017M611750).

Open Access This article is distributed under the terms of the Creative Commons Attribution 4.0 International License (http:// creativecommons.org/licenses/by/4.0/), which permits unrestricted use, distribution, and reproduction in any medium, provided you give appropriate credit to the original author(s) and the source, provide a link to the Creative Commons license, and indicate if changes were made.

Publisher's Note Springer Nature remains neutral with regard to jurisdictional claims in published maps and institutional affiliations.

\section{References}

1. Polmear IJ, StJohn D, Nie J.-F, and Qian M, Light alloys: metallurgy of the light metals

2. Geetha M, Singh AK, Asokamani R, Gogia AK (2009) Ti based biomaterials, the ultimate choice for orthopaedic implants - a review. Prog Mater Sci 54(3):397-425

3. Wang ZB, Hu HX, Zheng YG, Ke W, Qiao YX (2016) Comparison of the corrosion behavior of pure titanium and its alloys in fluoridecontaining sulfuric acid. Corros Sci 103:50-65

4. Palanivel R, Dinaharan I, Laubscher RF (2017) Microstructure evolution and mechanical characterization of Nd:YAG laser beam welded titanium tubes. Mater Charact 134:225-235

5. Wu M, Xin R, Wang Y, Zhou Y, Wang K, Liu Q (2016) Microstructure, texture and mechanical properties of commercial high-purity thick titanium plates jointed by electron beam welding. Mater Sci Eng A 677:50-57

6. Zhao Y, Wang W, Yan K, Liu C, Zou J (2018) Microstructure and properties of $\mathrm{Cu} / \mathrm{Ti}$ laser welded joints. J Mater Process Technol 257:244-249

7. Schneider A, Gumenyuk A, Lammers M, Malletschek A, Rethmeier M (2014) Laser beam welding of thick titanium sheets in the field of marine technology. Phys Procedia 56:582-590

8. Liu H, Shui J, Cai T, Chen Q, Song XG, Yang GJ (2018) Microstructural evolution and hardness response in the laser beam welded joints of pure titanium during recrystallization and grain growth. Mater Charact 145:87-95

9. Ascari A, Fortunato A, Guerrini G, Liverani E, Lutey A (2017) Long pulse laser micro welding of commercially pure titanium thin sheets. Procedia Eng 184:274-283

10. Yokohara K, Okamoto Y, Ochiai H, Kimura R, Ono S, Akase $M$ (2016) Investigation of shielding gas supplying method in vertical-position laser welding of pure titanium. Procedia CIRP 42:448-453

11. Zhan X, Peng Q, Wei Y, Ou W (2017) Experimental and simulation study on the microstructure of TA15 titanium alloy laser beam welded joints. Opt Laser Technol 94:279-289

12. Liu H, Nakata K, Zhang JX, Yamamoto N, Liao J (2012) Microstructural evolution of fusion zone in laser beam welds of pure titanium. Mater Charact 65:1-7

13. Kumar C, Das M, Paul CP, Bindra KS (2018) Comparison of bead shape, microstructure and mechanical properties of fiber laser beam 
welding of $2 \mathrm{~mm}$ thick plates of Ti-6Al-4V alloy. Opt Laser Technol 105:306-321

14. Li R, Li Z, Zhu Y, Rong L (2011) A comparative study of laser beam welding and laser-MIG hybrid welding of Ti-Al-Zr-Fe titanium alloy. Mater Sci Eng A 528(3):1138-1142

15. Acherjee B (2018) Hybrid laser arc welding: state-of-art review. Opt Laser Technol 99:60-71

16. XU G et al (2015) Numerical analysis of fluid flow in laser+gmaw hybrid welding. Acta Met Sin 51(6):713-723

17. Maawad E et al (2016) Influence of crystallographic texture on the microstructure, tensile properties and residual stress state of laserwelded titanium joints. Mater Des 101:137-145

18. Hahn EN, Meyers MA (2015) Grain-size dependent mechanical behavior of nanocrystalline metals. Mater Sci Eng A 646:101-134

19. Liu H, Nakata K, Yamamoto N, Liao J (2011) Mechanical properties and strengthening mechanisms in laser beam welds of pure titanium. Sci Technol Weld Join 16(7):581-585

20. Li C, Muneharua K, Takao S, Kouji H (2009) Fiber laser-GMA hybrid welding of commercially pure titanium. Mater Des 30(1): 109-114

21. Karpagaraj A, Siva shanmugam N, Sankaranarayanasamy K (2015) Some studies on mechanical properties and microstructural characterization of automated TIG welding of thin commercially pure titanium sheets. Mater Sci Eng A 640:180-189

22. Wang XY, Li WY, Ma TJ, Vairis A (2017) Characterisation studies of linear friction welded titanium joints. Mater Des 116:115-126

23. Mironov S, Sato YS, Kokawa H (2009) Development of grain structure during friction stir welding of pure titanium. Acta Mater 57(15):4519-4528

24. Shen J et al (2018) Microstructure evolution and mechanical properties of flash butt-welded Inconel718 joints. Mater Sci Eng A 718:34 42

25. Short $A B(2009)$ Gas tungsten arc welding of $\alpha+\beta$ titanium alloys: a review. Mater Sci Technol 25(3):309-324

26. Chen Z, Gao J, Yan K (2018) Formation of twin boundaries in commercial purity aluminum with addition of Ti refiner. Mater Lett 221:1-3
27. Ghaderi A, Barnett MR (2011) Sensitivity of deformation twinning to grain size in titanium and magnesium. Acta Mater 59(20):7824-7839

28. Gurao NP, Kapoor R, Suwas S (2011) Deformation behaviour of commercially pure titanium at extreme strain rates. Acta Mater 59(9):3431-3446

29. Liu H, Nakata K, Yamamoto N, Liao J (2010) Grain orientation and texture evolution in pure titanium lap joint produced by friction stir welding. Mater Trans 51(11):2063-2068

30. Wronski M, Arul Kumar M, Capolungo L, McCabe RJ, Wierzbanowski K, Tomé CN (2018) Deformation behavior of CP-titanium: experiment and crystal plasticity modeling. Mater Sci Eng A 724:289-297

31. Nixon ME, Lebensohn RA, Cazacu O, Liu C (2010) Experimental and finite-element analysis of the anisotropic response of high-purity $\alpha$-titanium in bending. Acta Mater 58(17):5759-5767

32. Pouraliakbar H, Jandaghi MR, Mohammadi Baygi SJ, Khalaj G (2017) Microanalysis of crystallographic characteristics and structural transformations in SPDed AlMnSi alloy by dual-straining. J Alloys Compd 696:1189-1198

33. Fernandes FAO, Oliveira DF, Pereira AB (2017) Optimal parameters for laser welding of advanced high-strength steels used in the automotive industry. Procedia Manuf 13:219-226

34. Kashaev N et al (2017) Microstructure and mechanical performance of autogenously fibre laser beam welded Ti-6242 butt joints. Mater Sci Eng A 694:110-120

35. Liu FC, Liao J, Gao Y, Nakata K (2015) Influence of texture on strain localization in stir zone of friction stir welded titanium. J Alloys Compd 626:304-308

36. Pouraliakbar H, Jandaghi MR, Heidarzadeh A, Jandaghi MM (2018) Constrained groove pressing, cold-rolling, and postdeformation isothermal annealing: consequences of their synergy on material behavior. Mater Chem Phys 206:85-93

37. Sarkari Khorrami M, Mostafaei MA, Pouraliakbar H, Kokabi AH (2014) Study on microstructure and mechanical characteristics of low-carbon steel and ferritic stainless steel joints. Mater Sci Eng A 608:35-45 